\title{
The Proper Formulation of the Overt Pronoun Constraint: Evidence from Persian and Azeri
}

\author{
Mohsen Jannejad
}

Shahid Chamran University of Ahvaz, Iran, Email: m_jannejad@yahoo.com

Reza Banari

SAMA Technical and Vocational Training College, Islamic Azad University, Baghmalek, Iran, Email: rezabanari2010@yahoo.com

Anahita Bordbar

Department of TEFL, Baghmalek Branch, Islamic Azad University, Ahvaz, Iran, Email: anahitabordbar@gmail.com

Ali Bardide

Academic Center of Education, Culture \& Research (ACECR), Khouzestan Branch, Iran, Email: abardideh@gmail.com

Doi:10.5901/mjss.2016.v7n4s2p176

\begin{abstract}
Generativists claim that there are some structural properties of the grammar that cannot be acquired solely on the basis of input. It is argued that such properties, known as principles, are part of UG common to all languages. The Overt Pronoun Constraint (OPC) principle, the focus of the present study, asserts that if in any language an alternation between overt/null pronouns be possible, the overt pronoun in an embedded clause cannot take a quantifier such as someone, everybody, and nobody as its antecedent in the main clause. To study OPC principle in four groups of speakers, namely Persian heritage, Persian monolingual, Azeri heritage, and Azeri monolingual, the present study gathered data from 20 participants in each group. Participants completed two comprehension tasks, i.e. a Picture-Matching Task (PMT), and a Sentence-Selection Task (SST). Both tasks tested the interpretation of the implicit knowledge of the OPC with quantified antecedents. All quantifiers were assumed to be treated equally in both tasks. Results of the SST revealed that there was no statistically significant difference between monolingual speakers of Persian and Azeri monolingual languages in understanding the interpretative contrast between overt and null pronouns within OPC contexts. Regarding the heritage speakers, it was found that they seemed to have problems with the OPC in the SST. As for the PMT, it was found that heritage speakers and monolinguals of both languages understood the interpretative contrast present with overt and null pronouns within OPC contexts with no significant difference between them.
\end{abstract}

Keywords: Overt Pronoun Constraint, heritage speakers, monolinguals, quantifier, pronoun

\section{Introduction}

There have been debates between the Generativist and Probabilistic approaches to language learning regarding the process of language development. The probabilistic approach holds that the statistical properties of the input language determine all or most of what happens in the process of language development. The proponents of this view argue that what appears as 'Universal Properties' is simply a by-product of the developmental system. They reject the existence of an independent innate module in favor of the 'acquisition of a large database of words and their statistical probabilities of co-occurrence' (Perez-Leroux \& Glass, 1999). Generativist approach, on the other hand, holds that there are structural properties of the grammar that cannot be acquired solely on the basis of input. The 'Poverty-of-Stimulus' argument, a byproduct of this approach, suggests that 'language learners attain knowledge of structural properties which are underdetermined by available input' (Perez-Leroux \& Glass, ibid).

The Overt Pronoun Constraint (OPC) (Montabelli, 1984; White, 2003) proposes that in [+null argument] languages, that is, languages allowing both null and overt pronouns such as Persian and Azeri, an overt pronoun cannot receive a bound variable interpretation. In other words, it cannot have a quantified expression such as everyone, no one, someone or a wh-phrase (e.g. who) as its antecedent. According to Montalbetti (1984), if the alternation between null and overt pronouns is allowed in a language, an overt pronoun in the embedded subject position cannot be bound by a quantified 
matrix subject. In order to shed more light on OPC, examples from English and Persian are given below.

The bound interpretation of the sentence below (derived from Montalbetti, 1984) requires he to refer to nobody, i.e., the pronoun he is bound by the quantifier expression outside its binding domain:

Nobody believes that he is intelligent.

Under the bound reading, the sentence above means that no member of a set believes that he-himself/she-herself is intelligent. Montalbetti (1984) illustrates the following underlying interpretation:

(No $x$ : $x$ a person) $x$ believes that $x$ is intelligent.

However, the English sentence above does not necessarily mandate a bound variable reading. The sentence involves a free reading; that is, the pronoun he can be free and co-referential with some entity other than the matrix subject. The free reading can be illustrated as:

(No $\mathrm{x}$ : $\mathrm{x}$ a person) $\mathrm{x}$ believes that $H E$ is intelligent.

Thus, the English sentence above is ambiguous. Nevertheless, Montalbetti (1984) argues that this ambiguity is resolved in pro-drop languages since in such structures the lexically realized pronoun "cannot be construed as a bound pronoun, while the phonologically-null one (pro) can".

Therefore, according to what Montalbetti (1984) calls OPC, both sentences below are ambiguous and unambiguous respectively:

Hichkasi fekr nemikonad ke proij bahooshast

no one thought does not that pro intelligent is

(No one thinks that he is intelligent)

Hichkasi fekr nemikonad ke 00j bahoosh ast

no one thought does not that s/he intelligent is

(No one thinks that he is intelligent)

Defining OPC, Montalbetti (1984) believes that "overt pronouns cannot link to formal variables if the alternation overt/empty obtains". As stated in the definition, OPC applies to languages in which overt pronouns can be substituted by null ones. Montalbetti (1984) also defines 'formal variables' in the following wa: " $\underline{v}$ is a formal variable iff (i) $\underline{v}$ is an empty categoryin an argument position; and $\underline{\mathrm{v}}$ is linked to a lexical operator in a non-argumentposition". Traces of "WHmovement' and of 'Quantifier Raising' constitute examples of formal variables.

Consequently, overt pronouns cannot be bound by a quantifier Noun Phrase (NP) unless they are linked to a pro which, in turn, is bound by the quantifier NP. In the sentence below, the overt pronoun oo can be bound by the quantifier NP hichkas by being linked to the intermediate pro:

Hichkasi nagoft ke proi fekr mikonad ke ooi bahoosh ast

no one said not that pro thought does that s/he intelligent is

(No one said that he thought that he was intelligent.)

Despite some arguments against the universality of OPC (Gurel, 2003; Sheen, 2000), this constraint has been used by several researchers (Kanno, 1997; Lozano, 2008; Peretz-Leroux \& Glass, 1999) as one instance of a universal principle. OPC is claimed to be universal for the following reasons (Lozano, 2002):

I. Similar effects can be found in other pro-drop Romance languages like Portuguese, Italian, and Greek and in typologically unrelated languages like Chinese and Japanese and Korean.

II. In learnability theory, OPC represents a typical case of a poverty of the stimulus phenomenon, since the ungrammatical construction [ ${ }^{*} \mathrm{QDPi}$ overti] is not present in the Spanish input (neither in L1 acquisition nor in L2 acquisition). Input in the form of positive evidence alone does not contain ungrammatical expressions. Therefore, OPC knowledge must be part of UG principles.

III. OPC constructions are never explained in textbooks. Therefore, instruction can be discarded as the source of knowledge of OPC.

Specifically speaking, the present study analyzes the level of maintenance of a property of the Null Subject Parameter (NSP), i.e. OPC, in Persian and Azeri monolinguals and heritage speakers. A heritage language is the language someone learning at home as a child, which is a minority language in society; however, because of growing up in a dominant language, the speaker seems to be more competent in the dominant language and feels more comfortable to communicate in that language (Polinsky \& Kagan, 2007). In current study, the interpretative abilities of Persian heritage speakers grown up in Azerbaijan (where Azeri is the dominant language), Persian monolinguals grown up in Iran (where Persian is the dominant language), Azeri heritage speakers grown up in Iran (where Persian is the dominant language), and Azeri monolinguals grown up in Azerbaijan (where Azeri is the dominant language) were examined. Two comprehension tasks, i.e. a Picture-Matching Task (PMT), and a Sentence-Selection Task (SST), were employed in order to test these speakers' interpretative abilities. 


\section{Literature Review}

A plethora of researchers have studies OPC in different languages. For instance, Kanno (1997), using 20 Japanese native speakers as the control group and 28 English speaking students learning Japanese at the University of Hawaii, tested subjects' knowledge of the contrast between null and overt pronouns in terms of the antecedent they take in Japanese. The sentences she used were as follow:

1. Null pronoun with a quantified NP as antecedent Whoi said that $\left(h_{i}\right)$ bought a car?

2. Overt pronoun with a quantified NP as antecedent Whoi said that hei bought a car?

3. Overt pronoun with a referring NP as antecedent Tanakai says that hei is the best in the company.

4. Null pronoun with a referring NP as antecedent Tanakai says that (hei) is the best in the company.

Having been presented with one of such sentences, the participant were asked a question like the one below:

Test sentence: Who said that he bought a car?

Question: Who do you suppose bought a car? a)Who b) another person c) both (a) \& (b)

It was revealed that the Japanese native speakers accepted the co-referentiality interpretation of the overt pronoun (47\%) when the antecedent was an NP, but they rejected it when the antecedent was a quantifier. The pattern of responses by non-native speakers was found very similar to that of native speakers in this regard.

In another study, Perez-Leroux and Glass (1999) aimed at studying whether OPC is operative in the early stages of acquisition of Spanish. They opted for 98 participants in 3 proficiency groups, i.e. elementary, intermediate, and advanced. They also included a control group with members from Latin America, Spain, and Caribbean. They used a set of 8 stories followed by a sentence to betranslated. The stories were designed in a way that the participants had to translate the given sentences with a referential NP as the antecedent of the pronoun in the embedded clause in four of the sentences; for the other four sentences, a bound variable interpretation was required.

Referential story: In the O.J. Simpson trial, it is clear that the press has a negative bias against the defendantin their reporting. Some journalist said that he was a wife beater.

- To translate: 'But no journalist said that he is guilty.'

- Target translation: Ningún periodistadijoqueél era culpable.

(No journalist said that HE was guilty).

Bound-variable story: The court charged that some journalists had been in contact with the jurors. Several ofthem were questioned by the judge.

- To translate: 'No journalist admitted that he had talked to the jurors.'

- Target translation: Ningún periodistaadmitúque le había hablado a los jurados.

(No journalist admitted that $\varnothing$ to-them-had spoken to the jurors.)

It was observed that all the proficiency groups could well distinguish between the two types of contexts in the use of overt pronouns. No group used the overt pronoun when the antecedent was a quantifier.

Lozano (2002) sought to explore whether L2 speakers are sensitive to OPC in L2 with such a principle and without such a principle. In so doing, he could determine whether L1 or UG is the source which learners use in processing. He opted for two groups of learners learning Spanish as L2. One group was English native speakers who did not follow OPC in their L1. The second group consisted of Greek native speakers who knew English and were learning Spanish. OPC is operative in Greek as in Spanish. They hypothesized that if both groups show almost the same response, it is reasonable to conclude that it is UG which is the 'source of transfer in non-native OPC contexts'.

An acceptability judgment test with a five-point Likert-Scale was used, in which a contextualized sentence was followed by two other sentences to be judged as in the following example:

El señor López y la señoraGarcía trabajan en la universidad y en unafamosa editorial.

No obstante...

(a) cadaestudiante dice queéltienepocodinero. $-2-10+1+2$

(b) cadaestudiante dice quetienepocodinero. $-2-10+1+2$

'Mr López and MsGarcía work at the university and at a famous publishers. However...'

'each student says that he has little money'

'each student says that has little money' 
It was observed that each group could discriminate between the ungrammatical construction (overt pronoun) and the grammatical construction (null pronoun). The between-group comparison showed that the English speakers and the Greek speakers did not differ from the Spanish natives in being sensitive to OPC. Since OPC is not operative in English, they concluded that learners' knowledge of OPC comes from UG rather than their L1.

Yamada (2002) sought to extend Kanno's (1997) study by examining L2 learners' knowledge of OPC in the embedded object position since embedded objects are also null in Japanese. She included both embedded subjects and objects as follows.

(I)

a. QNP ..... null subject $(n=3)$

Someone said that (he) had a camera.

b. RNP .... null subject $(n=3)$

Tanaka said that (he) would play the guitar tonight.

c. QNP ..... kare subject $(n=3)$

Someone was saying that he had a camera.

d. RNP ..... kare subject $(n=3)$

Tanaka said that he would play the guitar tonight.

(II)

a. QNP ..... null object $(n=3)$

Someone says that Tanaka will help (him) today.

b. RNP .... null object $(n=3)$

Masao was saying that John would help (him) tomorrow.

c. QNP ..... kare object $(n=3)$

Someone says that Tanaka will help him tomorrow.

d. RNP ..... kare object $(n=3)$

Koji says that Tanaka will help him tomorrow. example:

The participants were given a sentence like the ones above and were asked a question as in the following

Test sentence: someone was saying that he had a camera.

Question: Who do you suppose had a camera? a) Who b) another person c) both (a) \& (b)

They found that while the L2 speakers were similar in response patterns to the native speakers in case of the embedded subjects, they were quite different in the case of embedded objects. The L2 speakers allowed both null objects and kare to take QNP antecedents, but native speakers did not.

\section{Methodology}

Generativists believe that some principles are parts of UG and, therefore, common to all languages. OPC is one such principle, which has been explored in many pro-drop languages such as Spanish, Italian, Japanese, Greek, and Turkish. However, to the best knowledge of the researchers, OPC has not been explored in Persian and Azeri, which are also prodrop languages. What makes Persian and Azeri good areas of interest for such a study is their almost free word-order with some elements of a sentence being able to appear in more than one position. Since there has been no study so far exploring the operationality of OPC in Persian and Azeri, the present study can be a step toward filling such a gap. This present study looked at the interpretation possibilities of overt subject pronouns in the subordinate clause with a quantified or wh-word antecedent in monolinguals and heritage speakers of Persian and Azeri. All participants were asked to complete two tasks designed to test whether they could interpret sentences constrained by the OPC.

\subsection{Participants}

This study consisted of four participant groups, i.e. 20 monolingual Persian speakers (who grew up in Iran where the dominant language is Persian), 20 Persian heritage speakers (who grew up in Azerbaijan where the dominant language is Azeri), 20 monolingual Azeri speakers (who grew up in Azerbaijan where the dominant language is Azeri), and 20 Azeri heritage speakers (who grew up in Iran where the dominant language is Persian). In each group, there were eleven female and nine male subjects. Their age ranged from 19 to 40 with an average age of 29 years old at the time of study. 


\subsection{Instrument}

All participants, including both monolinguals and heritage speakers, were asked to complete two experimental tasks. The first task was a Sentence Selection Task (SST), and the second was a Picture-Matching Task (PMT). The SST tested the interpretation of a target bound reading (with the presence of a null subordinate subject) with quantified and wh-word antecedents, while the PMT tested the interpretation of bound and unbound readings (with the presence of both null and overt subordinate subjects) with quantified and wh-word antecedents. Both experimental tasks controlled for the type and occurrence of antecedents present in each token. The two tasks were multiple-choice and there were both Persian and Azeri versions of the tasks.

\subsection{Data Collection Procedures}

Having checked the reliability and the validity of the tasks, the final versions of the tasks were administered to the participants. Participants in the actual data sampling were instructed in their native language to facilitate their performing the tasks. Moreover, confidentiality of their responses was guaranteed and it was acknowledged that the study was conducted for a scientific research and their contribution was very valuable. No time limit was put for the tasks in order not to create anxiety on the learners' behalf. The first experimental task was SST. It was given first because it required that the participants pay attention to the context to be able to choose the correct option ((a), (b), or (c)). Next, participants were asked to complete PMT. This task required that participants to interpret the pictures according to the contexts provided. Both SST and PMT were provided through Microsoft Office PowerPoint (PPT) where participants were asked to read the slides and then mark their response on a printed answer sheet. The whole data collection procedure was conducted individually in a quiet room.

\subsection{Data analysis}

A paired-samples $t$-test was run in order to compare the means of the null and overt pronouns for each quantifier used in both tasks. Also, a one-way repeated-measures ANOVA was calculated to look at the differences between the three antecedent types used in this study.

\section{Results}

\subsection{Sentence Selection Task (SST)}

As described before, the purpose of SST was to test the participants' interpretation of null and overt subject pronouns in an embedded clause with strictly controlled quantified and wh-word antecedents. Participants were provided with a context and were asked to choose a logical concluding sentence for that context, choosing among three options. The context purposefully forced a bound reading between the embedded subject and the antecedent, which required them to recognize that the preferred option was the sentence choice that included the null subject in the subordinate clause. There were a total of 32 target scenarios, where four quantified antecedents and two wh-word antecedents were tested, with four tokens per antecedent type.

\subsubsection{Persian Monolinguals}

Figure 1 displays the overall results for the monolingual Persian participants. The results in the figure are grouped according to antecedent type (quantified, wh-word, and referential) to show how this group performed overall and which sentence they chose as their concluding sentence which contained one pronoun, i.e. null, overt, or both. Because the only acceptable answer was to choose the sentence with a null pronoun, the other two options were grouped together as one (overt/both) since both options are rendered as inadequate. 


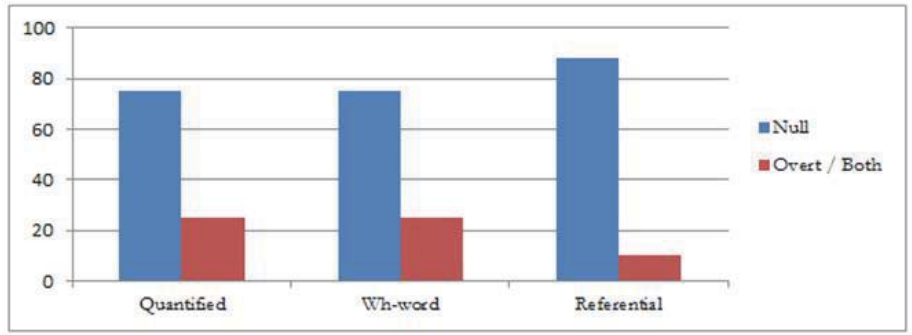

Figure 1. Monolingual Persian choice of null or overt subject based on grouped quantifiers

Based on the figure, participants chose the null option most frequently with referential antecedents (common names) at a rate of $89 \%$, and they chose the sentence with the null pronoun with quantified and wh-word antecedents at a rate of $75 \%$ and $74 \%$, respectively.

A paired samples $t$-test was run to compare the means of the null and overt pronouns for each antecedent type: Quantified, WH-word, and Referential. It is important to note that within the analysis for the SST, the 'overt' option also included the results for choosing 'both' as their option. These two means were grouped together because they were both considered to be the incorrect or unexpected response for the contexts provided. The results revealed that the difference in pronoun choice in the SST was significant for all antecedent types: Quantified $(M=0.431, S E=0.081, t(19)=5.334, p$ $<0.001)$; WH-word $(M=0.475, S E=0.078, t(19)=6.024, p<0.001)$; Referential $(M=0.762, S E=0.102, t(19)=7.494$, $p<0.001$ ). The results indicate that when being forced to choose the null subject, the participants understood the difference in interpretation between the two pronoun types.

A one-way repeated-measures ANOVA was also calculated to look at the difference between the three antecedent types (Quantified, WH-word, and Referential) in responding with a null subject pronoun. It was found that the type of quantifier had a significant effect, $F(2,38)=6.816, p=0.003$. Tests of a within-subjects contrast showed that the difference in responses between the quantified antecedents and the referential antecedents was significant, $F(1,19)=$ 12.55, $p=0.002$. A Bonferroni post hoc test showed that the difference between quantified and referential antecedents as well as between WH-word and referential antecedents was significant at $p<0.05$. However, there was no significant difference between quantified and WH-word antecedents at $p<0.05$.

\subsubsection{Persian Heritage speakers}

Figure 2 displays the overall results for the Persian heritage speaker group. Unlike previous results, the figure shows that this group of subjects chose the null option very similarly across the board. However, the quantified antecedents provided a slightly higher null pronoun response at a rate of $59 \%$. Moreover, they responded at a rate of $58 \%$ with both wh-word and referential antecedent types.

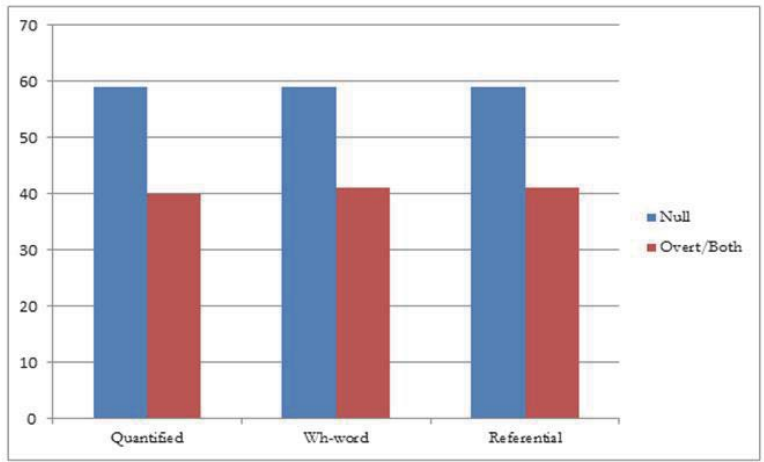

Figure 2. Heritage Persian choice of null or overt subject based on grouped quantifiers 
A paired-samples $t$-test was used to compare the means of the null and overt subjects for each antecedent type when responding to SST. The results of the $t$-test showed that even though Persian heritage speakers appeared to be responding more appropriately in choosing the null pronoun, there was no significant difference in the two pronoun choices: Quantified $(M=0.168, S E=0.083, t(19)=2.030, p>0.05)$; WH-word $(M=0.162, S E=0.121, t(19)=1.347, p$ $>0.05)$; Referential $(M=0.163, \mathrm{SE}=0.131, \mathrm{t}(19)=1.239, \mathrm{p}>0.05)$.

Also, a one-way repeated-measures ANOVA was calculated and the results showed that the type of antecedent did not have a significant effect, $F(2,38)=0.008, p=0.992$.

A MANOVA was run to look at the difference between the monolingual and heritage Persian speaker groups and their choice regarding the null and overt/both options. It was found that there was a significant difference between the two speaker groups and the antecedent types $(p<0.05)$. That is to say, the Persian heritage speakers appeared to differ from the Persian monolinguals in how they interpreted the null pronoun and overt pronouns in the subordinate clause. The monolinguals appeared to respond stronger with the referential antecedents; however, the heritage speakers appeared to treat all the antecedents in the same manner.

\subsubsection{Azeri Monolinguals}

Figure 3 displays the overall results for the monolingual Azeri participants. Based on the figure, participants chose the null option most frequently with referential antecedents (common names) at a rate of $83 \%$, and they chose the sentence with the null pronoun with WH-word and quantified antecedents at a rate of $72 \%$ and $64.75 \%$, respectively.

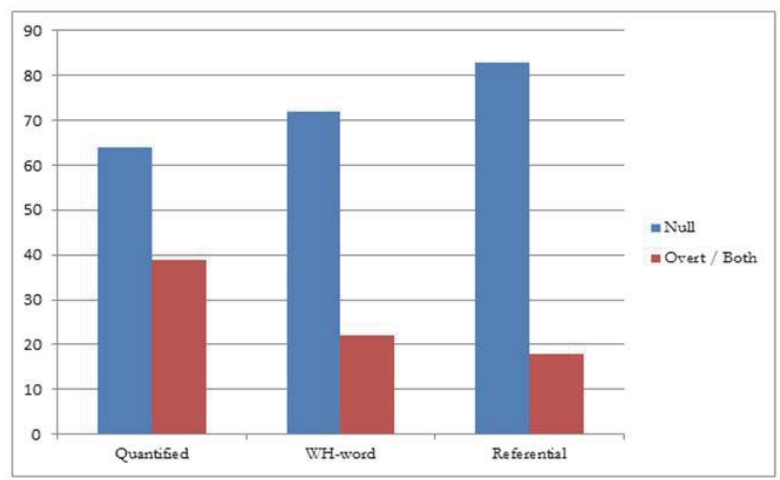

Figure 3. Monolingual Azeri choice of null or overt subject based on grouped quantifiers

A paired-samples t-test was used to compare the means of the overt and null pronouns in SST. The results showed that the difference in the choice between the two pronouns was significant: Quantified $(M=0.294, S E=0.114, t(19)=2.575$, $p<0.05)$; WH-word $(M=0.437$, SE = 0.105, $t(19)=4.145, p<0.01)$; Referential $(M=0.650, S E=.114, t(19)=5.710$, $p<0.001)$. These results indicate that Azeri monolinguals distinguish between the two pronoun types when responding to an $\mathrm{OPC}$ context.

Also, a one-way repeated-measures ANOVA was used to calculate the significance of the quantifier type looking specifically at Azeri monolinguals. The results showed that the quantifier type was not significant within the language group of the Azeri monolinguals, $F(2,38)=1.089, p>0.05$.

\subsubsection{Azeri heritage speakers}

Figure 4 displays the overall results for the Azeri heritage speaker group. Similar to the results discussed in Section 4.1.2 on Persian heritage speakers, the referential antecedents were not the antecedent group that received the most null pronoun responses. In fact, Figure 4 shows that this group of participants chose the null pronoun sentences the most with quantified antecedents at a rate of $58 \%$. Next, it was the wh-word antecedents at a rate of $52 \%$ and, finally, the referential antecedents at a rate of $47 \%$. 


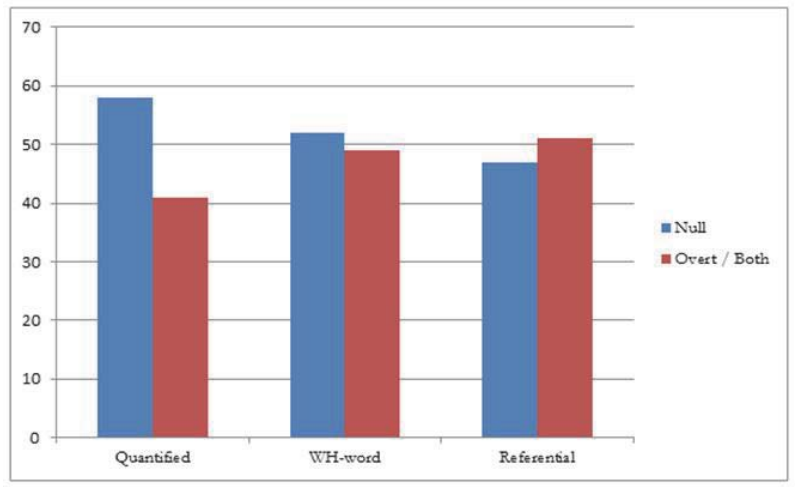

Figure 4. Heritage Azeri choice of null or overt subject based on groupedquantifiers

A paired-samples $t$-test was used to compare the means of the null and overt pronouns that were chosen by the Azeri heritage speakers in SST. The expected response in this task was to choose the token sentence with the null pronoun. The results showed that, on the whole, Azeri heritage speakers did not differentiate between the null and overt pronouns in each antecedent type $(p>0.05)$.

Also, a one-way repeated-measures ANOVA was calculated to test the significance between the quantifier types used. Mauchly's test indicated that the assumption of sphericity was violated $\left(X^{2}(2)=9.83, p<0.05\right)$; therefore, degrees of freedom were corrected using Greenhouse-Geisser estimates of sphericity $(\bullet=0.70)$. The results showed that the type of quantifier was not significant, $F(1.41,26.75)=1.144, p>0.05$.

Moreover, a MANOVA was run to compare the means of both monolingual and heritage Azeri speaker groups looking at how they responded with each antecedent type and the pronoun choice (null or overt/both). The results showed that there was no significant difference between the null and overt choices with the quantified antecedents, $F$ ( 1 , $38)=0.806, p>0.05$; however, there was a significant difference between the rest of the antecedent types and the null/overt subject choice $(p<0.05)$.

\subsubsection{Comparison of Heritage Speakers and Monolinguals}

A comparison was done between the Persian heritage speakers and the Azeri heritage speakers in order to see whether there was any difference between two heritage speaker populations, and, also, how they chose the subject for contexts within SST. Looking at the two heritage speaker groups, they appeared to be responding very similarly across the board when choosing both subjects, i.e. null and overt. An independent-samples t-test was run to compare the means between the Persian heritage speakers and the Azeri heritage speakers in their responses in choosing the null and overt/both subject options for all three antecedent types. The results showed that there was no significant difference between the two speaker groups and how they chose the null or overt/both subjects $(p>0.05)$.

Also, a comparison of the Persian and Azeri monolingual speakers was done in order to see whether their responses aligned in terms of choosing a null or overt subject or in stating that both options were adequate. Both groups appeared to be responding identically in how they chose the null subject and for each quantifier type. An independentsamples t-test was used to compare the means between Azeri monolinguals and Persian monolinguals in the subject choice in SST, namely null vs. overt/both. The analysis also took the antecedent types into account. The results showed that there was no statistically significant difference between how the two groups chose the null and overt subjects for each antecedent type $(p>0.05)$. These results indicate that both null subject languages are functioning similarly in SST.

\subsection{Picture-Matching Task (PMT)}

As described before, the purpose of PMT was to test the participants' interpretation of null and overt subject pronouns in an embedded clause with strictly controlled quantified and wh-word antecedent types. Participants were provided with a context followed by two pictures and a target sentence that was underneath both pictures (each target scenario was presented on one PPT slide). Based on the target sentence, participants were asked to indicate which picture best 
depicted that final sentence. It was assumed that participants indicated their interpretation of that target sentence by choosing one of the two pictures. There were a total of 64 target sentences, where four quantified antecedents and two wh-word antecedents were tested, with eight tokens per antecedent type. Additionally, there were 16 tokens of referential antecedents that were common names in order to see how participants reacted to antecedents that do not fall within OPC.

\subsubsection{Persian Monolinguals}

Figure 5 provides the overall results for the monolingual Persian participant group when there was an overt pronoun or a null pronoun in the target sentence. Similar to previous sections, the results in this figure are grouped according to antecedent type, i.e. quantified, wh-word, and referential, to show the overall accuracy of this group and which picture they chose as the one depicting the concluding sentence that contained either an overt or null pronoun. The presence of the null subject indicates to the reader of the sentence (token) that the preferred interpretation is that where the null pronoun is bound to its quantified antecedent. The presence of the overt subject requires the reader to know that the overt subordinate subject pronoun cannot be bound to its antecedent and it must refer to a third party within the discourse (it must be unbound). The results showed that when the null subject was present in the subordinate clause, participants responded correctly with quantified antecedents at a rate of $70 \%$. With Wh-word antecedents, Persian monolinguals responded at a rate of $61 \%$, and with referential antecedents, they responded with $91 \%$. When the overt pronoun was present in the subordinate clause, participants responded correctly at a rate of $68 \%$ with quantified antecedents, $73 \%$ with Wh-word antecedents, and $67 \%$ with referential antecedents.

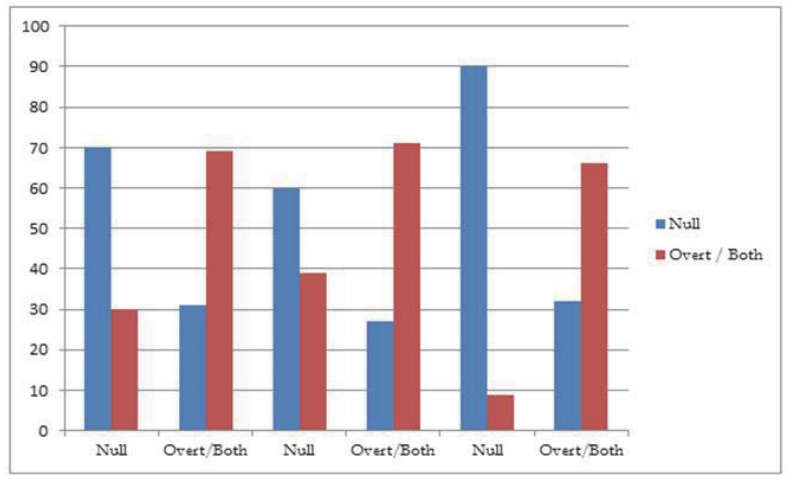

Figure 5. Monolingual Persian correct interpretation of overt and null subjects based on group quantifiers

A paired-samples t-test was run to compare the means of the correct responses with the null pronoun (choosing a bound reading) to the uncanonical responses for the null pronoun (choosing an unbound reading), looking at the three antecedent types. The results showed that there was a significant difference between the expected and unexpected responses for the null pronoun for all antecedent types, indicating that they were making a difference between bound and unbound readings in the null pronoun context $(p<0.01)$.

Also, a paired-samples t-test was run to compare the means of the correct responses with the overt pronoun (choosing an unbound reading) to the unexpected responses for the overt pronoun, where choosing a bound reading violates OPC. The results showed that there was a significant difference in their choice of subject interpretation with the overt pronoun $(p<0.01)$. These results indicate that these monolinguals are distinguishing between the null and overt pronouns in their interpretation possibilities.

\subsubsection{Persian Heritage speakers}

Figure 6 provides overall results for the Persian heritage participant group when there was a null or overt pronoun in a target sentence. The results are interpreted as the participants providing a bound or unbound reading, depending on which picture was chosen. The results showed, when looking at the null pronoun, participants chose the bound option 
most frequently with referential antecedents at a rate of $96 \%$; next, it was the quantified antecedents at a rate of $70 \%$ and wh-word antecedents at a rate of $61 \%$. The presence of the overt pronoun indicates that there can only be an unbound reading (in red) as OPC states. A bound reading is not possible in null subject languages, but it is possible in English. Figure 6 further shows that participants chose the unbound option most frequently with the wh-word antecedents at a rate of $68 \%$; next, it was the quantified antecedents at a rate of $63 \%$ and, finally, the referential antecedents at a very low rate of $39 \%$.

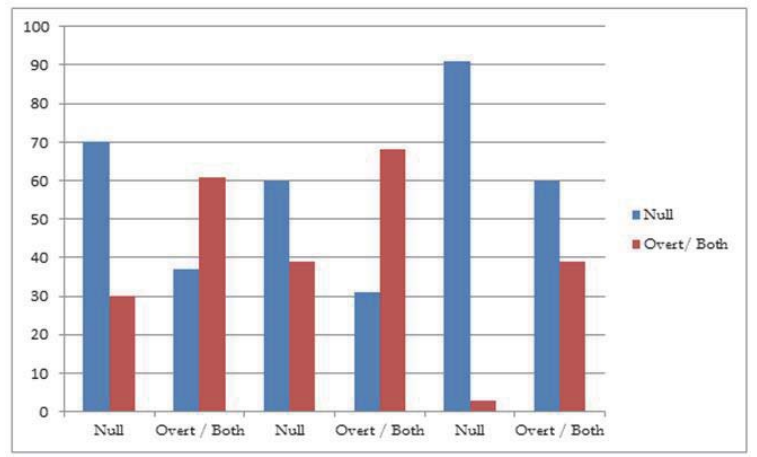

Figure 6. Heritage Persian interpretation of null and overt subjects based on group quantifiers

A paired-samples $t$-test was run to compare the means between the null responses (bound vs. unbound) to see whether there was any difference in how participants were treating the null pronoun. The results showed that there was a significant difference between the bound and unbound interpretations with the null pronoun within each antecedent type $(p<0.01)$. These results indicate that participants are not randomly choosing one type of interpretation with the null pronoun in the subordinate clause; rather, they are showing that they prefer a bound reading.

Further, a paired-samples t-test was used to compare the means of the overt pronoun interpretations (bound vs. unbound), where the unbound reading is the one that does not violate OPC. The results showed that there was a significant difference in their interpretation of the overt pronoun in the subordinate clause $(p<0.01)$ with all antecedent types, except for the referentials where there was no significant difference $(p<0.01)$. These results show that the heritage speakers do interpret the sentences well.

A MANOVA was run to compare the means of both monolingual and heritage Persian speaker groups looking at how they responded with each antecedent type and the pronoun choice (null or overt/both). The results show that there was very minimal difference between how the two speaker groups interpreted the overt pronoun with quantified and whword antecedents, $F(1,38)=0.806, p>0.05$; however, there was a greater contrast in how they treated the referential antecedents $(p<0.05)$.

\subsubsection{Azeri Monolinguals}

Figure 7 provides overall results for the monolingual Azeri participant group when there was a null pronoun in a target sentence. The results were interpreted as the participant providing a bound or unbound reading, depending on which picture was chosen. The results showed when there was a null subject pronoun in the subordinate clause, participants chose the bound option most frequently with referential antecedents at a rate of 73\%; next, it was the quantified antecedents at a rate of $69 \%$ and wh-word antecedents at a rate of $68 \%$. The presence of the overt pronoun indicates that there can only be an unbound reading (in red) as the OPC states. A bound reading is not possible in null subject languages, but it is possible in English. As Figure 7 shows, participants chose the unbound option most frequently with quantified antecedents at a rate of $67 \%$; next, it was the wh-word antecedents at a rate of $60 \%$ and referential antecedents at a rate of $59 \%$.

A paired-samples $t$-test was run to compare the means of responses when the null subject was in the subordinate clause target sentence. The comparison looked at the canonical-bound interpretation (in blue with the null pronoun) with the non-canonical (but also expected) unbound reading (in red). The results showed that there was a significant difference between the bound and unbound readings for null pronouns, indicating that these speakers were not randomly 
choosing a bound reading with a null pronoun: quantified $(M=0.352$, $S E=0.057, t(19)=6.118, p<0.001)$; WH-word (M $=0.312, \mathrm{SE}=0.090, \mathrm{t}(19)=3.455, \mathrm{p}<0.01)$; referential $(\mathrm{M}=0.462, \mathrm{SE}=0.055, \mathrm{t}(19)=8.373, \mathrm{p}<0.001)$.

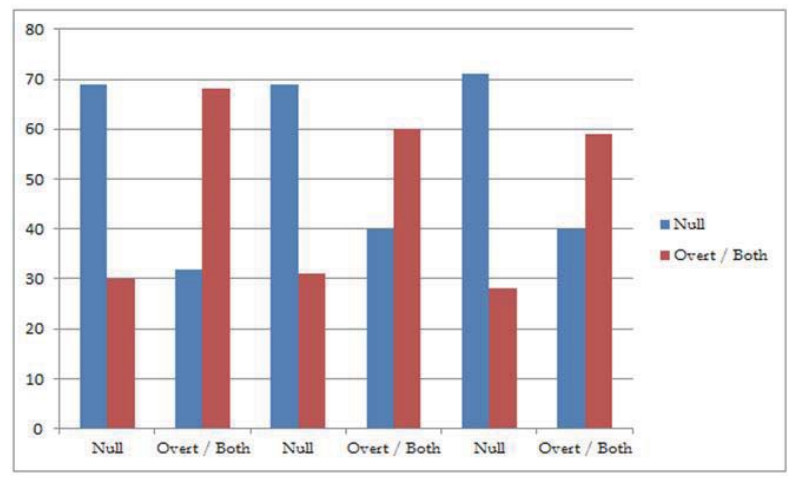

Figure 7. Monolingual Azeri interpretation choice of null and overt subjects based on group quantifiers

Finally, a paired-samples t-test was run to compare the means of the responses to the overt pronoun in the subordinate clause with each antecedent type (OPC context). The results showed that there was a significant difference between the bound and unbound readings with the overt pronoun with quantified antecedents $(M=0.339, S E=0.063, t(19)=5.360$, $p<0.001)$, and with WH-word antecedents $(M=0.250, S E=0.116, t(19)=2.153, p<0.05)$. These results indicated that participants were not choosing random pictures when the overt pronoun was in the subordinate clause of the target sentence. These participants were, in fact, obeying OPC.

\subsubsection{Azeri Heritage Speakers}

Figure 8 provides the overall results for the Azeri heritage participant group when there was a null or overt pronoun in a target sentence. The results were interpreted as the participant providing either a bound or unbound reading, depending on which picture was chosen. The results showed when the null subject pronoun was present in the subordinate clause, participants chose the bound option most frequently with referential antecedents at a rate of $97 \%$; next, it was the quantified antecedents at a rate of $72 \%$ and wh-word antecedents at a rate of $67 \%$. The presence of the overt pronoun indicates that there can only be an unbound reading (in red) as OPC states. Figure 8 shows that when the overt subject pronoun was present participants chose the unbound option most frequently with the wh-word antecedents at a rate of $54 \%$; next, it was the quantified antecedents at a rate of $53 \%$ and, finally, the referential antecedents at a very low rate of $23 \%$.

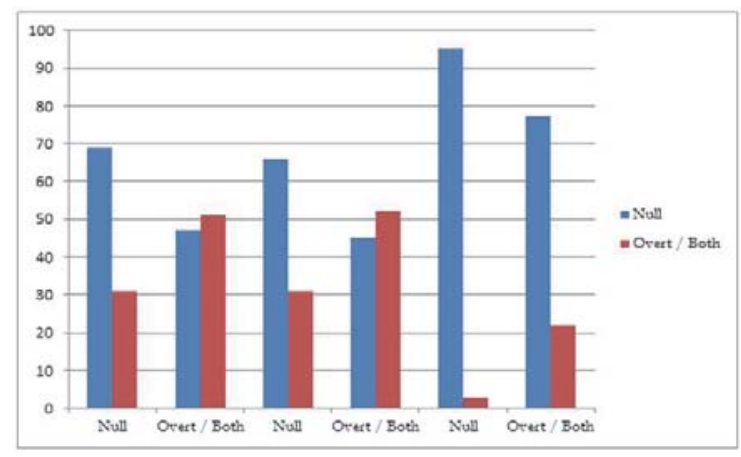

Figure 8. Bound and unbound readings with null and overt pronouns for Azeri heritage speakers in PMT 
A paired-samples $t$-test was run to compare the means of the responses to the presence of the null pronoun in the subordinate clause (bound vs. unbound), looking at the three different antecedent types. The results showed that there was a significant difference between the bound and unbound interpretations with the null pronoun $(p<0.01)$. These results indicate that participants prefer to provide a bound reading with the null pronoun.

Also, a paired-samples $t$-test was run to compare the means of the responses to the presence of the overt subject in the subordinate clause, which is the context for OPC. It is expected that participants know that there should be an unbound reading with the overt pronoun. Just as Figure 24 shows, the results from the $t$-test demonstrate that there is no significant difference in how these heritage speakers are responding to the overt pronoun in the subordinate clause $(p<$ 0.01). These results indicate that participants are unsure of what to do with the overt pronoun.

A comparison was done between the Azeri monolinguals and heritage speakers in how they responded in PMT, specifically looking at how they interpreted the overt and null subject pronouns. An independent-samples $t$-test was run to analyze the means of responses to null (ambiguous reading) and overt pronouns in the subordinate clause (an OPC context). The results showed that there was a statistical difference between the two speaker groups with the quantified antecedents when the pronoun was overt $(\mathrm{M}=0.135, \mathrm{SE}=0.048, \mathrm{t}(38)=2.817, \mathrm{p}<0.01)$ and with the referential antecedents for both null and overt pronouns $(M=0.356, S E=0.089, t(28.347)=3.981, p<0.001)$.

\subsubsection{Comparison of Heritage Speakers and Monolinguals}

A comparison of the two heritage speaker groups was done in order to see whether there was any similarity between their interpretation possibilities of the overt subject pronoun in the subordinate clause, given that both languages are nullsubject languages, but they are from two distinct language families. An independent-samples $t$-test was run to compare the means of correct (unbound) and incorrect (bound) responses with the presence of the overt pronoun in the subordinate clause (OPC context) with the different antecedent types between the two heritage groups. The results showed that there was no significant difference between the two groups in terms of response to the quantified antecedents $(p>0.05)$; however, there was a significant difference in the two heritage groups with the WH-word antecedents $(\mathrm{M}=0.137, \mathrm{SE}=0.058, \mathrm{t}(38)=2.354, \mathrm{p}<0.05)$, and with the referential antecedents $(\mathrm{M}=0.156, \mathrm{SE}=$ $0.074, t(38)=2.102, p<0.05)$.

A comparison was done between Azeri and Persian monolinguals looking at how they responded to the overt subject pronoun with quantified, WH-word, and referential antecedents. This comparison was done in order to better understand the type of cross-linguistic variation that exists between two null-subject languages. An independent-samples $t$-test was run to compare the means between Azeri and Persian monolinguals of correct (unbound) and incorrect (bound) responses to the presence of an overt pronoun in the subordinate clause, looking at the three antecedent types. The results showed that there was no significant difference between the two monolingual groups in how they treated the overt pronoun when it was in the subordinate clause and within the context of OPC.

\section{Discussion and Conclusion}

Results from SST found that Persian monolinguals and Azeri monolinguals responded very similarly to each other. It was reported that no significant difference was found between these two speaker groups. The same results were found when comparing the Azeri heritage speakers to the Persian heritage speakers, showing that both groups are similar in their interpretation possibilities of the overt pronoun. There was a significant difference between the responses by the Azeri monolinguals and Azeri heritage speakers, and between the Persian monolinguals and Persian heritage speakers.

Looking at how the heritage speakers responded in SST, it appeared as though they were having problems with OPC in this task. In this task, in particular, they were to notice that the null subject was the correct response and at the same time that the overt pronoun would violate the restrictions of OPC. The results showed that the responses of these speakers did differ significantly between the null and overt pronouns.

The results from PMT were not as clear-cut as they were with SST since there was a difference in how the two tasks were designed. The SST did not leave too much room for personal interpretation because the contexts were set up to force one specific reading. The PMT, on the other hand, employed the use of pictures and asked participants to provide their own interpretations of sentences that were formulated following OPC. Overall, results showed that there was no significant difference between the two monolingual groups in this task. When comparing the two heritage speaker groups, there was no significant difference when looking at the quantified antecedents, but there was a difference with the WH-word antecedents, pointing to these antecedents once again. When comparing the Azeri monolinguals to their heritage speakers, there was a significant difference in their interpretations of the overt pronoun with quantified 
antecedents; however, they appeared to be treating the overt pronoun similar to WH-word antecedents. Looking at the Persian monolinguals and their heritage speakers, there was no significant difference in how they interpreted the overt pronoun, indicating that the Persian heritage speakers do have OPC. Both monolingual groups were able to distinguish between bound and unbound interpretations when the overt pronoun was present in the subordinate clause. Also, the Persian heritage speaker group appeared to differentiate between bound and unbound interpretations with the overt pronoun. The only group that appeared to be having difficulties was the Azeri heritage speaker group. It is possible that if there were more participants in this group, the results would line up more with that of the Persian heritage speakers since an inter-group comparison finds that there was no difference between their interpretations of the overt pronoun for both tasks.

An area which requires further research is the replication of this study with other native speaker heritage languages in order to see whether similar contrasts appear in SST and PMT. This analysis is necessary in order to be able to conclude whether the contrasts found between the four antecedents are due to a task effect or some type of change is happening in the interpretation of these specific quantifiers.

\section{References}

Gürel, A. (2003). Is the overt pronoun constraint universal? Evidence from L2 Turkish. In J. M. Liceras et al. (Eds.), Proceedings of the 6th Generative Approach to Second Language Acquisition Conference (pp. 130-139). Somerville, MA: Cascadilla Proceedings Project.

Kanno, K. (1997). The acquisition of null and overt pronominals in Japanese by English speakers. Second Language Research 13(3), 265-287.

Lozano, C. (2002). The interpretation of overt and null pronouns in non-native Spanish. Durham Working Papers in Linguistics, 8, 53-66.

Lozano, C. (2008). The acquisition of syntax and discourse: Pronominals and word order in English and Greek learners of Spanish. Saarbrücken, Germany: VDM Verlag Dr. Müller Aktiengesellschaft \& Co. KG.

Montalbetti, M., M. (1984). After binding. On the interpretation of pronouns. Unpublished Ph.D. Dissertation. MIT, Cambridge, Mass.

Pérez-Leroux, A. T., \& William R. G. (1999). Null anaphora in Spanish second language acquisition: Probabilistic versus generative approaches. Second Language Research 15 (2), 220-249.

Polinsky, M., \& Kagan, O. (2007). Heritage languages: In the 'wild' and in the classroom. Language and Linguistics Compass, 1(5), 36895.

Sheen, R. (2000). A response to Kanno's "The stability of UG principles insecond-language acquisition: Evidence from Japanese". Linguistics, 38 (4),799-816.

White, L. (2003). On the nature of inter-language representation: universal grammar in the secondlanguage. In C. J. Doughty, \& M. H. Long (Ed.), Second language acquisition. Oxford: Blackwell Publishing Ltd.

Yamada, K. (2002). The status of the Overt Pronoun Constraint in grammatical theory and SLA of Japanese. Essex Graduate Student Papers in Language and Linguistics, University of Essex. 